\title{
Controle Social em Educação Básica Pública
}

\author{
Social Control in Public Elementary Education
}

\author{
Maria Abádia da Silva ${ }^{1}$ \\ Marcus Vinicius de Azevedo Braga²
}

\section{RESUMO}

Este estudo examina o controle social na educação básica pública e analisa a atuação do Estado brasileiro para exercê-lo sobre a população e os instrumentos dessa mesma população para controlar esse Estado, em uma sociedade de classes marcada pelas desigualdades sociais e econômicas. A partir de categorias de Antonio Gramsci, discute a luta dos trabalhadores pelo direito à educação pública e como estes reinventam formas de participação por meio de conselhos na educação, principalmente no que tange à aplicação dos recursos orçamentários e aos mecanismos que instituem a gestão democrática na educação básica pública.

Palavras-chave: Controle social; Gestão da educação; Educação básica pública.

\begin{abstract}
This study examines the social control in basic public education and examines the actions of the Brazilian state to exercise it on the population and the instruments of the same population to control this state in a class society marked by social and economic inequalities. From Antonio Gramsci discusses categories of the workers' struggle for the right to public education and how they are reinventing forms of participation by counsel in education, especially regarding the implementation of budgetary resources and establishing mechanisms to democratic management in education Basic public.

Key-words: Social Control; Education

Administration; Public Basic Education.
\end{abstract}


Trata-se de um estudo desenvolvido no Programa de Pós-Graduação em Educação, da Faculdade de Educação da Universidade de Brasília, na linha de Políticas Públicas e Gestão da Educação Básica, e tem como objeto o controle social na educação básica pública. Uma parte deste estudo, apresentado a seguir, analisa o conceito de controle social no que se refere à questão da aplicação correta e equilibrada dos recursos financeiros públicos, juntamente com outras formas inventadas pela população para o acompanhamento e monitoramento de uma educação de e com qualidade social.

O direito à educação básica pública se efetiva também por meio de práticas e medidas que dão transparência e permitem aos sujeitos controlarem e fiscalizarem o uso de verbas públicas aplicadas nas atividades educacionais. Assim, a ideia de analisar a construção do conceito de controle social em educação contribui, desse modo, para impulsionar a gestão democrática na educação básica pública, incidindo também nos sistemas de ensino e na escola, como destinatária principal dos recursos financeiros.

Propomos, então, os seguintes objetivos: problematizar o conceito de controle social na educação básica pública e analisar algumas medidas de atuação do Estado para exercer o controle sobre a população e os instrumentos da população para controlar o Estado, em uma sociedade de classe marcada pelas desigualdades sociais e econômicas.

\section{Aproximações acerca do controle social na educação básica pública}

No Estado capitalista, a política social tornouse um dos elementos utilizados para manter o equilíbrio entre a dominação e a reprodução do capital, abstraindo dos trabalhadores certo consenso no atendimento de demandas focalizadas. O controle social, nesse prisma, é sinônimo de luta pela garantia de direitos sociais, de ação dos menos favorecidos para ocupar espaços de viabilização desses direitos, ainda que possa, contraditoriamente, tornarse um instrumento político de dominação e de coerção do Estado.
Se o Estado capitalista surge com a função de manter o domínio de uma classe sobre a outra, como pode esse Estado permitir ser controlado pela classe dominada? Nesse sentido, um controle para promover o bem de todos não seria compatível com o objetivo de capitanear lucros e privilégios para os donos dos meios de produção, função precípua do Estado capitalista. Essa contradição mostra o Estado capitalista como um palco de lutas, acomodação de interesses políticos e econômicos. Como bem assevera Correia (2008, p. 116):

A sociedade civil não é homogênea, mas espaço de lutas de interesses contraditórios. As lutas não são da sociedade civil contra 0 Estado, mas de setores que representam os interesses do capital e do trabalho (ou de desdobramento desta contradição, como a exclusão de gênero, etnia, religião, a defesa de direitos, da preservação do meio ambiente, entre outras lutas específicas) na sociedade civil e no Estado em busca da hegemonia.

O Estado e a sociedade civil, compreendidos como arena de lutas, na concepção de Antonio Gramsci serve de suporte teórico para analisar a estratégia de atuação das classes populares diante dos instrumentos de controle social. Neste caso, os conselhos de educação são formas de ocupação de espaços no aparelho estatal, na luta pelos interesses e na conquista de direitos sociais.

A categoria guerra de posição, oriunda do pensamento gramsciano, da sua teoria ampliada do Estado, evidencia formas de ocupação das classes, nos espaços do Estado, para a defesa de seus interesses. Nesse conceito, a estratégia de ocupação do poder pelos trabalhadores não pode ser uma estratégia de confronto direto, como na chamada guerra de movimento, que foram exitosas nos países classificados por Gramsci como orientais ${ }^{3}$. Neles, a busca de posições e espaços, da direção político-ideológica e do consenso dos setores majoritários da população, tornou-se condição para o acesso ao poder do Estado (COUTINHO, 1989, p. 89).

3 Gramsci chamava de orientais aqueles países em que a dominação se dava mais pela coerção do que pelo consenso, o que demandava estratégias de ação mais diretas, de cunho revolucionário, na chamada "guerra de movimento". Os países por ele chamado ocidentais eram aqueles em que a dominação se dava mais pelo consenso, demandando da classe subalterna formas mais sutis de ação na chamada "guerra de posição". 
Essa reflexão Gramsci fez pela análise dos sucessivos fracassos da revolução nos países ditos ocidentais, em face de sua característica menos despótica e mais liberal. Sabemos que essas características se acentuaram na realidade vigente, onde a tecnologia e a comunicação de massa permitem formas de dominação mais sutis dos grupos ou setores hegemônicos, com traços de ideologia democrático-liberal, fazendo da estratégia da guerra de posição o seu fio condutor. Essa perspectiva coloca a luta pela hegemonia como uma ação processual de setores econômicos em direção à ocupação do poder.

Portanto, na "guerra de posição" que atravessa uma crise de hegemonia, preparando-a ou dandoIhe progressivamente solução, não há lugar para a espera messiânica do "grande dia", para a passividade espontaneísta que conta com a irrupção de uma explosão do tipo catastrófico como condição para o "assalto ao poder". 0 critério central para a decisão da crise é a iniciativa dos sujeitos políticos coletivos, a capacidade de fazer política, de envolver grandes massas na solução de seus próprios problemas, de lutar cotidianamente pela conquista de espaços e posições, sem perder de vista 0 objetivo final de promover transformações de estrutura que ponham fim à formação econômico-social capitalista (COUTINHO, 1989, p. 93-94).

Essa visão de guerra de posição municia e aparelha os trabalhadores, mesmo em momentos de opressão, mostrando o caminho da luta e da resistência, pela via política. Nessa visão, a "guerra de posição é baseada na ideia de cercar o aparelho do Estado com uma contra-hegemonia, uma hegemonia criada pela organização de massa da classe trabalhadora" (CARNOY, 1990, p. 29).

A cada ciclo de crises o capitalismo atual (2010) cria mecanismos de reprodução e exploração cada vez mais sutis, ao mesmo tempo as associações, entidades e movimentos sociais reinventam maneiras de reivindicar os direitos e mais espaços públicos para vivenciar processos de cidadania, entre eles os diversos conselhos ligados às questões da educação básica pública em todo país. Nesses conselhos os sujeitos se apropriam de conhecimentos para acompanhar, fiscalizar e controlar o cumprimento de regras, leis e princípios, na luta cotidiana pela materialização do direito à educação básica.
O controle social não é do Estado e sim dos setores, dos grupos sociais. São mecanismos efetivados por meio de ações, medidas e regras impetradas pelos sujeitos sob a maneira de como o Estado capitalista age na sociedade. É por meio do controle social que os trabalhadores, movimentos sociais, entidades, sindicatos e associações pressionam e confrontam a gestão pública na formulação das políticas, na direção de seus anseios e na luta pela construção de seus direitos.

Assim, o controle social são ações, medidas e práticas inventadas e realizadas pelos sujeitos, pela via democrática que pressionam as políticas e medidas definidas pelos governos. São ações cotidianas intencionais, coletivas ou individuais, materializadas em formas participativas de atuar $\mathrm{e}$ propor na sociedade, organizada ou não, o controle e o acompanhamento das políticas públicas, desde a sua formulação até a sua implementação.

Neste sentido, o controle social envolve a capacidade que as classes subalternas, em luta na sociedade civil, têm para interferir na gestão pública, orientando as ações do Estado e os gastos estatais na direção dos interesses destas classes, tendo em vista a construção de sua hegemonia (CORREIA, 2005, p. 64).

Desse modo, o controle social é entendido como uma conquista da população decorrente de luta, em uma sociedade civil heterogênea e plural. O entendimento é que os interesses das forças dominantes, instaladas hegemonicamente no aparelho estatal, defrontam-se com as ações e reivindicações dos trabalhadores, dos movimentos sociais, associações e entidades que se tornaram protagonistas e exigem transparência e controle social sobre as políticas públicas, em especial sobre os recursos financeiros. As novas sutilezas da dominação capitalista exigem uma permanente reinvenção dos mecanismos de participação, de mobilização e de ações dos sujeitos para o atendimento de seus interesses, de suas demandas e das propostas vindas das comunidades locais.

\section{A luta pelo controle social em educação básica pública}

a) 0 império e as suas marcas na educação nacional

Em termos financeiros, desde o período jesuítico o controle estatal ocorria na medida em que a coroa 
portuguesa executava seus planos de exploração. Os poucos recursos aplicados na educação vinham da igreja católica e somente nos idos de 1759, com a reforma pombalina e a expulsão dos jesuítas, com o advento do subsídio literário ${ }^{4}$ municipal para as aulas-régias $^{5}$, que os recursos oriundos de tributos passaram a ser destinados à educação pública (MONLEVADE, 2001).

Ainda sim, o processo era voltado quase que exclusivamente paraa cobrança, paraamanutenção dos fluxos financeiros, não se importando como se dava a aplicação desses recursos e como estavam sendo atingidas as finalidades da educação.

Nesse contexto, a educação continuou sendo um privilégio para poucos e muito distante da participação popular, dos destituídos dos direitos elementares. Quanto ao aspecto do financiamento público faltavam recursos humanos e financeiros para abrir e manter as escolas, ainda que a igreja católica continuasse mantendo uma rede de ensino e de atividades educativas.

A Lei Geral da Educação de $1827^{6}$ garantia ensino público e gratuito a todas as vilas, freguesias e povoados do país, denotando a influência dos ventos democráticos europeus. Apesar de ser um direito positivado, pouco dizia o texto da Lei sobre quem iria garanti-lo, ou seja, quem afiançaria a sua materialização junto à comunidade, o que fazia de um direito uma letra morta. Durante as regências, as revoltas e insurreições caracterizaram os intentos de separação política, ao mesmo tempo em que fincavam os alicerces de um modelo de relação entre as províncias e o governo central (FARIAS; VIEIRA, 2007).

Ainda de maneira tímida, nas províncias criaram-se algumas escolas de primeiras letras,

\footnotetext{
4 Subsídio literário, 1772, foi um tributo destinado a custear as reformas no campo da instrução promovidas pelo Marquês de Pombal e era vinculado a um determinado valor por quantidade de um determinado produto vendido.
}

5 Com a reforma pombalina e a expulsão dos Jesuítas, a educação nacional passou a utilizar o sistema de aulas-régias, que consistiam em um sistema público, mas que visava primordialmente às elites.

6 Lei Imperial de 15 de outubro de 1827, manda criar escolas de primeiras letras em todas as cidades, vilas e lugares mais populosos do Império. esparsas por todo território, marcadas pela descentralização do ensino. A escola pública e gratuita, distribuída nas províncias de forma insuficiente, marcou o início da educação pátria, como um direito negado e controlado, um privilégio para poucos, os abastados da sorte.

O Ato Adicional da Constituição Imperial de 1824 desatou o nó e indicou os poderes responsáveis "pelo atendimento e garantia dos direitos educacionais" (MONLEVADE, 2001, p. 32), pelo menos nos aspectos financeiros, indicando o Imposto de Vendas e Consignação (IVC) como financiador da educação pública, em um primário processo de vinculação de tributos a educação.

No que tange ao controle sobre "a desordem social", os gritos dos representantes da população foram ocultados no âmbito da existência do direito à educação, mas não nas ações efetivas, dada a carência reinante.

O Ato adicional (1834) criou as Câmaras Municipais em cada vila, vilarejos, freguesia ou cidade, o que indicou um embrião da representação local, atribuindo a estas funções no âmbito educacional (FARIAS; VIEIRA, 2007), inspecionando as escolas de primeiras letras e o destino de órfãos pobres, como semente da ação popular organizada na fiscalização da execução da política pública. Apesar dessa iniciativa, concomitante ao processo de descentralização da educação publica para as províncias, a fiscalização prevista não logrou êxito e predominou uma sociedade escravista, patrimonialista e latifundiária, com uma parcela significativa de analfabetos à margem social (FARIAS; VIEIRA, 2007).

\section{b) Ser cidadão é participar da vida pública}

Na República, os traços de desigualdades e privilégios para poucos continuaram. A mudança do regime de governo e os ventos republicanos pouco alteraram o quadro de abandono em que se encontrava a educação pública no país. A separação política também foi fruto de um processo acordado entre as elites, conduzido por monarquistas e militares, de forma a agregar as oligarquias agrícolas à cúpula do poder. A república erguia-se sob a herança de negação de direitos. E ao fortalecer, no âmbito regional, a oligarquia cafeeira inseriu-se no aparelho do 
Estado e minou o fortalecimento de iniciativas de controle social e de participação popular.

Desse modo, a República velha representou um continuísmo de alguns dos aspectos da administração pública imperial, representado num pacto das elites para manter as forças populares sobre controle, envolvendo também a educação pública, mantida descentralizada e sem diretriz orgânica e sistemática.

Os anos da República de 1930 a 1946 foram tensos no país, tensão que culminou com o golpe de estado em 1937, na instauração do Estado Novo, de traço declaradamente autoritário e que demarcou o viés da política educacional, conforme assevera Freitag (1980, p. 52):

A Política educacional do Estado Novo não se limita a simples legislação e sua implantação. Essa política visa, acima de tudo, transformar o sistema educacional em um instrumento mais eficaz de manipulação das classes subalternas.

A ação educacional se viu nas teias do autoritarismo, associando a necessidade de mão de obra para o processo de industrialização nascente, com uma política educacional com foco no ensino médio profissional para os trabalhadores, sob o discurso e a prática, nos moldes do populismo vigente.

No financiamento e no controle da educação pública, a Constituição Federal de 1934, pela primeira vez vinculou os recursos orçamentários para aplicação nesse fim, estabelecendo um mecanismo legislativo e quantitativo de controle do que se gastava em educação, dado que os recursos financeiros da educação, historicamente, seguem outros caminhos de retorno político mais rápido. Com a Constituição Federal de 1937, esse avanço da vinculação de recursos para a educação público foi abolido.

$\mathrm{Na}$ Constituição Federal de 1946 a vinculação de recursos orçamentários para a educação volta a figurar no texto constitucional, rotina que se repetiu em toda distensão de regimes autoritários na história brasileira. O texto constitucional de 1946 apresenta também a necessidade da União colaborar com Estados e Municípios no desempenho de suas funções educacionais, em uma descentralização próxima do ideal dos pioneiros de 1932 e similar ao paradigma adotado pela Constituição Federal de 1988 e a Lei de Diretrizes e Bases da Educação Nacional n. ${ }^{\circ} 9394$ de 1996.

O texto da Lei n. ${ }^{\circ} 4.024$ de 1961 (LDB) estabeleceu restrições relativas à organização contábil e à probidade das organizações para a concessão de bolsas custeadas pelo Erário, ainda que os complexos aspectos de controle envolvidos na transferência de recursos para particulares no desempenho de ações de caráter público não tenham sido considerados explicitamente, como a questão da prestação de contas dos recursos recebidos e a participação social na fiscalização desses recursos.

No que tange à participação popular, o artigo 8. ${ }^{\circ}$ da LDB de 1961 apresenta: O Conselho Federal de Educação será constituído por vinte e quatro membros nomeados pelo Presidente da República, por seis anos, dentre pessoas de notável saber e experiência, em matéria de educação.

Neste caso, a referência ao Conselho Federal de Educação como forma de assegurar a participação da sociedade na educação, demonstra um embrião da participação via conselhos nas políticas educacionais. No art 6. ${ }^{\circ}$ dessa mesma LDB, a figura do controle da ação educacional centralizada aparece novamente, em "O Ministério da Educação e Cultura exercerá as atribuições do Poder Público Federal em matéria de educação."

\section{c) O controle nas ações dos militares}

De 1964 a 1985, mais uma vez a sociedade brasileira se vê imersa em um regime autoritário. Professores e estudantes desaparecidos, universidades invadidas, uma ebulição de formalismocíviconocotidiano, censura, cassações e repressão são algumas das ocorrências desse período em relação à educação brasileira.

Movimentos populares de alfabetização são fechados e desqualificados (CUNHA; GÓES, 1996) e o Decreto-Lei n. ${ }^{\circ} 477$, de 26 de fevereiro de 1969, estabeleceu como infração disciplinar o professor, aluno ou servidor desempenhar atividades subversivas, instalando, assim, o braço repressivo da ditadura e a patrulha ideológica nos bancos universitários.

Nos aspectos do financiamento da educação, a Constituição Federal de 1967 manteve a linha de fortalecimento do ensino particular por bolsas 
e subvenções (FREITAG, 1980), expandindo a atuação do ensino particular no segmento fundamental. O Ministério da Educação foi ocupado por representantes da linha privatista, onde defender recursos públicos para a escola pública virou coisa de comunista (CUNHA; GÓES, 1996).

A influência dos Organismos Internacionais passou a se fazer mais presente, em especial na construção dos conceitos de controle social em educação.

De maneira crescente, o Banco Mundial, desde os anos de 1960, tem participado de forma sistemática e direta no âmbito educacional, com capacidade para intervir e formular políticas educacionais para a América Latina, menos pelo montante de empréstimos aprovados e mais pela sagacidade de manipular benefícios retirados das políticas sociais (SILVA, 2002, p. 58).

Esse alinhamento trouxe, além das questões geopolíticas, recursos novos para os técnicos da ditadura utilizarem na administração vigente, carente da prática de concursos públicos e outras formas democráticas e transparentes de gestão. Esses organismos, para executar o controle, ressignificaram a categoria "comunidade" como unidade consensual (SOUZA, 2008), com interesses comuns, para a ordem e o progresso, formando um todo monolítico que representava o anseio das pessoas e o bem comum.

A reforma de ensino de $1 .^{\circ}$ e $2 .^{\circ}$ graus, a Lei n. ${ }^{\circ}$ 5.692, de 11 de agosto de 1971, marcou a educação no regime militar e manteve a diretriz de transferência de recursos para o âmbito privado, vinculou os recursos às condições de funcionamento, não entrando nos aspectos da efetividade e da prestação de contas dos recursos recebidos, nem da sua transparência.

\section{d) Reinventar as formas de lutas pelos direitos sociais}

No fim do governo militar, em tempos de abertura, a promulgação da Constituição Federal de 1988 possibilitou o retorno dos ideais de descentralização das políticas sociais, mormente as educacionais, com a instalação de um correspondente paradigma de controle social com um viés técnico-fiscalizatório. Os mecanismos de controle instalados tinham como modelo a garantia de uma supremacia dos governantes municipais, em conselhos criados de forma artificial para garantir os recursos, como um substituto na gestão do papel que cabia aos órgãos de controle institucionalizados.

A descentralização e a participação popular, concebidas nos textos legais para permitir, no paradigma reinante, uma maior fiscalização da atuação estatal, esbarra em questões da historicidade de nosso povo e na sua relação com o Estado, comexperiências de participaçãofictaeuma fiscalização corroborante de desvios, malversação e corrupção. Uma esfera pública que, a despeito de toda a tecnologia e normatização, padece na sua gênese das relações neopatrimonialistas e de mecanismos próprios do Estado capitalista que enfraquecem a atuação popular.

Associado a esse fato, no período pós-ditadura houve o reconhecimento de novos sujeitos como interlocutores políticos, para a refundação de uma ordem democrática, acompanhado de um agravamento da miséria que alçou a agenda nacional a ajustes estruturais, a focalização de políticas sociais e a diminuição das ações dos sindicatos pela flexibilização do trabalho, o que enfraqueceu os movimentos sociais (RAICHELIS, 2000). Fez com que a participação popular, nas questões de controle estatal, fosse reinventada, em face de sua histórica relação com o Estado brasileiro, em uma ocupação de outros espaços criados nos embates políticos que, ainda, permanecem, quase no plano fiscalizatório.

\section{Considerações finais}

No campo educacional, o processo histórico das políticas educacionais conduziu a uma segmentação do controle social, concentrado em um viés fiscalizatório, de tom burocrático. Osfóruns de acompanhamento da gestão, materializados nos Conselhos de Acompanhamento, pouco se comunicam com as instâncias de participação na formulação da política, gerando um distanciamento entre a política educacional e as questões do seu controle e financiamento ao alcance da população.

Esse predominante caráter fiscalizatório nas instâncias de participação é perceptível nos modelos de controle social do Fundo de Manutenção e Desenvolvimento da Educação Básica e de Valorização dos Profissionais da 
Educação (Fundeb) e do Programa Nacional de Alimentação Escolar (PNAE), dado que os conselheiros possuem tarefas atinentes à análise documental de processos de prestação de contas, como suportes ao controle institucional promovido pelos Tribunais de Contas, à semelhança de uma instância intermediária desses órgãos, de composição popular.

O controle social da política educacional, concebido como uma invenção social para se transformar em um instrumento de garantia do direito à educação pública dos trabalhadores, necessita de uma conceituação e de uma prática que considere o aspecto classista da sociedade e as contradições presentes na história do país. E assim, romper a aparência e adentrar na essência, nas contradições herdadas e ocultas de um longo processo histórico de negação de direitos.

As rupturas consensuadas, os pactos pelo alto e a demora pelo reconhecimento da educação como um direito social, e ainda, as alternâncias frequentes de regimes autoritários, colocaram os mecanismos de controle da política educacional inicialmente com um viés repressor, chegando aos anos de 1990, já sob a influência de organismos internacionais, com um perfil técnico-fiscalizador. Desse modo, a participação social em educação é vinculada à repartição de tarefas entre o Estado e a comunidade, na execução de tarefas programadas no sistema educacional vigente. Entretanto, esse quadro de instrumentos de participação restritivos da ação popular, com tarefas de cunho técnico, não pode inibir que os sujeitos sociais busquem se apropriar dessas instâncias, para que, como espaço de luta por direitos garantam aí, no combate aos desvios, que os recursos financeiros destinados no orçamento às políticas educacionais cheguem aos seus destinatários da melhor forma possível para assim impulsionar uma educação de qualidade social.

\section{Referências bibliográficas}

CARNOY, Martin. Educação, economia e Estado: base e superestrutura, relações e mediações. $4^{0}$ ed. São Paulo: Cortez: Autores Associados, 1990.

CORREIA, Maria Valéria Costa. Controle Social na Saúde. In: MOTA, Ana Elizabete et al. Serviço Social e Saúde: formação e trabalho profissional. 3. ed. São Paulo: Cortez, 2008.

CORREIA, Maria Valéria Costa. O conselho nacional de saúde e os rumos da política: mecanismo de Controle Social frente às condicionalidades dos organismos financeiros internacionais. 2005. 344 f. Tese (Doutorado) - Curso de Serviço Social, Universidade Federal de Pernambuco, Recife, 2005.

COUTINHO, Carlos Nelson. Gramsci: um estudo sobre seu pensamento político. Rio de Janeiro: Editora Campus, 1989.

CUNHA, Luis Antônio; GÓES, Moacyr de. O golpe na Educação. $9^{\circ}$. ed. Rio de Janeiro: Jorge Zahar Editora, 1996.

FARIAS, Isabel Maria Sabino de; VIEIRA, Sofia Lerche. Política Educacional no Brasil: introdução histórica. Braśilia: Liber Livro, 2007.

FREITAG, Bárbara. Escola, Estado e Sociedade. 4 . ed. rev. São Paulo: Moraes, 1980.

MONLEVADE, João. Educação Pública no Brasil: contos e descontos. 2º . ed. Ceilândia, DF: Idéia Editora, 2001.

RAICHELIS, Raquel. Esfera pública e Conselhos de assistência social: caminhos da construção democrática. $2^{\circ}$. ed. rev. São Paulo: Cortez, 2000.

SILVA, Maria Abádia da. Intervenção e consentimento: a política educacional do Banco Mundial. Campinas, SP: Autores Associados: Fapesp, 2002.

SOUZA, Rodriane de Oliveira. "Participação e controle social". In: SALES, Mione Apolinário; MATOS, Maurílio Castro de; LEAL, Maria Cristina (Org.). Política social, família e juventude: uma questão de direitos. $3^{\circ}$. ed. Rio de Janeiro: Cortez, 2008. 